\title{
Inhibition of microbial sulfate reduction in a flow-through column system by (per)chlorate treatment
}

\author{
Anna Engelbrektson ${ }^{1}$, Christopher G. Hubbard ${ }^{2}$, Lauren M. Tom ${ }^{2}$, Aaron Boussina ${ }^{1}$, Yong T. Jin ${ }^{1}$, \\ Hayden Wong ${ }^{1}$, Yvette M. Piceno ${ }^{2}$, Hans K. Carlson' ${ }^{1}$, Mark E. Conrad ${ }^{2}$, Gary Anderson ${ }^{2}$ and \\ John D. Coates ${ }^{1,2 *}$
}

${ }^{1}$ Department of Plant and Microbial Biology, University of California, Berkeley, Berkeley, CA, USA

2 Earth Sciences Division, Lawrence Berkeley National Laboratory, Berkeley, CA, USA

Edited by:

Matthew Youngblut, University of

California, Berkeley, USA

\section{Reviewed by:}

Lisa Gieg, University of Calgary,

Canada

Ian M. Head, Newcastle University, UK

Gerrit Voordouw, University of

Calgary, Canada

*Correspondence:

John D. Coates, Department of Plant and Microbial Biology,

University of California, Berkeley,

271 Koshland Hall, Berkeley,

CA 94720, USA

e-mail: jdcoates@berkeley.edu
Microbial sulfate reduction is a primary cause of oil reservoir souring. Here we show that amendment with chlorate or perchlorate [collectively (per)chlorate] potentially resolves this issue. Triplicate packed columns inoculated with marine sediment were flushed with coastal water amended with yeast extract and one of nitrate, chlorate, or perchlorate. Results showed that although sulfide production was dramatically reduced by all treatments, effluent sulfide was observed in the nitrate $(10 \mathrm{mM})$ treatment after an initial inhibition period. In contrast, no effluent sulfide was observed with (per)chlorate (10 mM). Microbial community analyses indicated temporal community shifts and phylogenetic clustering by treatment. Nitrate addition stimulated Xanthomonadaceae and Rhizobiaceae growth, supporting their role in nitrate metabolism. (Per)chlorate showed distinct effects on microbial community structure compared with nitrate and resulted in a general suppression of the community relative to the untreated control combined with a significant decrease in sulfate reducing species abundance indicating specific toxicity. Furthermore, chlorate stimulated Pseudomonadaceae and Pseudoalteromonadaceae, members of which are known chlorate respirers, suggesting that chlorate may also control sulfidogenesis by biocompetitive exclusion of sulfate-reduction. Perchlorate addition stimulated Desulfobulbaceae and Desulfomonadaceae, which contain sulfide oxidizing and elemental sulfur-reducing species respectively, suggesting that effluent sulfide concentrations may be controlled through sulfur redox cycling in addition to toxicity and biocompetitive exclusion. Sulfur isotope analyses further support sulfur cycling in the columns, even when sulfide is not detected. This study indicates that (per)chlorate show great promise as inhibitors of sulfidogenesis in natural communities and provides insight into which organisms and respiratory processes are involved.

Keywords: perchlorate reduction, petroleum microbiology, souring, sulfate reduction, sulfur

\section{INTRODUCTION}

Although non-traditional energy sources such as bioethanol, solar, and wind will increase over the coming decades, it is predicted that these will account for less than $10 \%$ of total demand by 2030 (US Department of Energy: www.eia.doe.gov/oiaf/ieo/ index.html). As such, global reliance on fossil energy and oil recovery will likely continue to dominate in the near future. An important aspect of oil recovery is control of reservoir biosouring, which is the result of in situ hydrogen sulfide $\left(\mathrm{H}_{2} \mathrm{~S}\right)$ biogeneration, typically after initiation of secondary recovery processes involving injection of sulfate-rich seawater (Youssef et al., 2009; Gieg et al., 2011).

As the primary cause of industrial gas inhalation deaths in the US (https://www.osha.gov/SLTC/hydrogensulfide/hazards. html), the generation of $\mathrm{H}_{2} \mathrm{~S}$ by sulfate reducing microorganisms (SRM) poses significant health (Fuller and Suruda, 2000) and environmental risks and results in a variety of oil recovery problems, including contamination of crude oil, metal corrosion, and precipitation of metal sulfides that plug pumping wells (Vance and Thrasher, 2005). Representatives within the domains Archaea and Bacteria have been identified as SRM contributing to souring in oil reservoirs. As such, targeting of specific species, genera, or even phyla for inhibition is of limited value. Because of this, efforts have focused on mechanisms by which the dissimilatory sulfate-reducing metabolism can be inhibited.

Intensive research has centered on thermodynamic inhibition of SRM by the addition of nitrate to the injection waters (Voordouw et al., 2009; Youssef et al., 2009; Hubert, 2010; Gieg et al., 2011). Thermodynamic considerations indicate that microbial nitrate reduction is energetically more favorable than sulfate reduction and should therefore occur first (Lovley and Chapelle, 1995). For example the Gibbs free energy for the anaerobic degradation of toluene coupled to nitrate reduction $\left(\Delta G^{o^{\prime}}=\right.$ $-3529 \mathrm{kJmol}^{-1}$ toluene) is significantly higher than that coupled 
to sulfate reduction ( $\Delta G^{o^{\prime}}=-179 \mathrm{kJmol}^{-1}$ toluene) (Rabus and Heider, 1998). While bio-competitive exclusion may operate in some systems, the favorable thermodynamics of nitrate reduction does not exclude the prospect that sulfate reduction can still occur if the electron donor is saturating (Lovley and Goodwin, 1988), as is the case in an oilfield. The electron acceptor being consumed at any specific location is controlled by the respective concentrations of the electron donor and individual electron acceptors (Lovley et al., 1995; Coates et al., 1996b, 2001; Christensen et al., 2000). Thus, as nitrate depletes in the near-well environment, or in microenvironments within the reservoir matrix, sulfate reduction can still be active deeper in the reservoir (Voordouw et al., 2009; Callbeck et al., 2011). While nitrite, a transient intermediate of nitrate reduction, can have a significant inhibitory effect on SRM (Callbeck et al., 2013), it is also chemically and biologically labile and has a limited half-life in a reduced reservoir matrix. Furthermore, the Nrf nitrite reductase is widely distributed amongst the known SRM, and has been demonstrated to provide an intrinsic defense mechanism against nitrite toxicity (Greene et al., 2003). Finally, nitrate addition also enriches for lithoautotrophic sulfur oxidizing nitrate reducing bacteria that oxidize sulfide to sulfate and mask the activity of active SRM (Gevertz et al., 2000). As such, in order to ensure inhibition of active sulfate reduction it is imperative to maintain a nitrate concentration in injection fluids high enough to prevent nitrate depletion during its residence in the formation and biogenesis of large quantities of nitrite (Callbeck et al., 2013). Under these conditions, nitrate addition can successfully impede SRM activity (Sunde and Torsvik, 2005) although not necessarily completely attenuate it (Callbeck et al., 2013). However, this requires the addition of saturating amounts of nitrate, which is not always financially feasible or logistically possible.

Here we investigate a novel strategy to biologically control biogenic $\mathrm{H}_{2} \mathrm{~S}$ generation based on the introduction of (per)chlorate into injection waters and the stimulation of the activity of dissimilatory (per)chlorate reducing bacteria (DPRB) in oil reservoirs. The advantage of this approach is that in addition to thermodynamic preference $\left(E^{o^{\prime}}=+797 \mathrm{mV}\right.$ and $+792 \mathrm{mV}$ for the biological couple of $\mathrm{ClO}_{4}^{-} / \mathrm{Cl}^{-}$and $\mathrm{ClO}_{3}^{-} / \mathrm{Cl}^{-}$, respectively) relative to sulfate reduction $\left(E^{o^{\prime}}=-217 \mathrm{mV}\right)$, previous studies (Postgate, 1952; Baeuerle and Huttner, 1986) demonstrated that high concentrations of (per)chlorate may be directly and specifically inhibitory to microbial sulfate-reduction. This is in contrast to nitrate inhibition which is primarily due to the production of the toxic transient intermediate nitrite (He et al., 2010). An additional aspect of souring treatment by (per)chlorate is based on the fact that while these compounds are kinetically stable in the presence of sulfide (Gregoire et al., 2014), all DPRB tested to date innately oxidize $\mathrm{H}_{2} \mathrm{~S}$ rapidly (Bruce et al., 1999; Coates et al., 1999; Coates and Achenbach, 2004), preferentially utilizing it over labile organic electron donors and producing benign elemental sulfur as the sole end product of the metabolism (Gregoire et al., 2014).

In our studies, advective flow column systems were packed with marine sediment through which we pumped seawater to assess the comparative effectiveness of nitrate, perchlorate, and chlorate in controlling souring. The progress of souring and the utilization of the added treatments (nitrate, chlorate, or perchlorate) was monitored by analyzing influent and effluent geochemistry and sulfur isotopes, while community $16 \mathrm{~S}$ ribosomal RNA gene analysis was used to gain insight into the shifts in microbial community composition.

\section{MATERIALS AND METHODS COLUMN SETUP AND OPERATION}

Triplicate flow-through columns were constructed from sealed $50 \mathrm{~mL}$ glass syringes packed with a mixture of about $50 \%$ San Francisco Bay sediment (microbial inoculum) and about 50\% glass beads (70-100 $\mu \mathrm{m}$ diameter, used to improve column permeability). The constructed columns were flooded with autoclaved anoxic (boiled and degassed with $\mathrm{N}_{2}$ ) San Francisco Bay water (19-33 mM sulfate concentration) containing 1 g.L $\mathrm{L}^{-1}$ yeast extract as a non-selective labile carbon source. Treatments consisted of $10 \mathrm{mM}$ sodium nitrate, $10 \mathrm{mM}$ sodium chlorate, $10 \mathrm{mM}$ sodium perchlorate, or a no treatment control. The treatment concentration was briefly reduced to $5 \mathrm{mM}$ for all three treatments at day 35 for a period of 3 days and then returned to $10 \mathrm{mM}$ to study the impact of lower treatment concentration on the column geochemistry. The control columns were unchanged during this time period. All four treatments were run with triplicate columns and identical flow rates. During the initial 28 days of the study, the columns were continuously flooded at $0.1 \mathrm{~mL} \cdot \mathrm{min}^{-1}$ for 2 days (estimated retention time $2.78 \mathrm{~h}$ ) with subsequent 2 days of no feed. After 20 days the flow rate was decreased to $0.025 \mathrm{~mL} . \mathrm{min}^{-1}$ (2 days of flow at $0.025 \mathrm{~mL} / \mathrm{min}$ followed by 2 days of no flow). Continuous flow at $0.025 \mathrm{~mL} \cdot \mathrm{min}^{-1}$ was established from day 28 with an estimated retention time of $11.11 \mathrm{~h}$ and a variance of less than $1 \%\left( \pm 0.00025 \mathrm{~mL} \cdot \mathrm{min}^{-1}\right)$. The columns were run for a total of 51 days. As total flow was very similar between all columns regardless of treatment, a cross-comparison of column treatments could be reasonably achieved.

\section{ANALYTICAL TECHNIQUES}

Nitrate, chlorate, and sulfate anions were quantified by ion chromatography on a Dionex IC 1500 using an AS9-HC anionexchange column with a $9 \mathrm{mM}$ sodium carbonate mobile phase at a flow rate of $1 \mathrm{~mL} \cdot \mathrm{min}^{-1}$. Perchlorate was quantified on a Dionex IC 2100 equipped with an AS16-HC anion-exchange column (Dionex IC2100) with a 25-65 mM potassium hydroxide gradient at a flow rate of $1 \mathrm{~mL} \cdot \mathrm{min}^{-1}$. Sulfide concentrations were quantified using a Cline assay (Cline, 1969) read at $660 \mathrm{~nm}$ on a Varian Cary 50 Bio spectrophotomer equipped with a Cary 50 MPR microplate reader.

Sulfur isotope analysis of dissolved sulfate was conducted on samples selected from one replicate column of each treatment. Sulfate was first precipitated as barium sulfate by adding excess barium chloride. The precipitate was rinsed three times in deionized water before being dried for analysis and sulfur isotope ratios were measured using a Eurovector 3028 elemental analyzer in helium continuous flow mode with a GV Isoprime isotope ratio mass spectrometer. Instrumental precision as assessed on external standards was $\pm 0.2 \%$. Sulfur isotope ratios are reported in standard delta notation, $\delta^{34} \mathrm{~S}=\left(\mathrm{R}_{\text {sample }} / \mathrm{R}_{\text {std }}-1\right) \times 1000$, where 
$R={ }^{34} \mathrm{~S} /{ }^{32} \mathrm{~S}$, and the value is reported in per mil (\%0) units relative to the Canyon Diablo Troilite standard $\left(\mathrm{R}_{\mathrm{std}}=0.0441216\right)$.

\section{PhyloChip}

To characterize changes in the microbial community due to the various treatments sediment samples were collected from the top (outlet) of the columns, DNA was isolated from the initial columns before flow began (designated inoculum) and from each of the triplicate columns for each treatment at four other time points (Days 31, 38, 42, and 51) using a Mo Bio PowerSoil DNA isolation kit (Mo Bio Laboratories, Inc., Carlsbad, CA) following the manufacturers protocol. DNA was quality assessed by agarose gel electrophoresis. PCR amplification was conducted as previously described (Wrighton et al., 2008); the amplifications used 1 ng of gDNA as template and were performed over an 4-gradient annealing temperature (4 PCR reactions were performed for each sample within a 50-56 C gradient and pooled) using nondegenerate primers $27 \mathrm{f}$ ( $5^{\prime}$-AGAGTTTGATCCTGGCTCAG-3') and 1492r (5'-GGTTACCTTGTTACGACTT). PCR amplifications were restricted to 25 cycles. PCR reactions were prepared for PhyloChip analysis and data were treated as previously described (Handley et al., 2012).

\section{COMMUNITY ANALYSES}

PhyloChip data was analyzed using PRIMER 6 (PRIMER-E Ltd, Plymouth, UK) and Excel (Microsoft Co, Redmond, WA). OTU data was square root transformed and normalized. Hierarchical clustering based on group average (the mean distance apart of two groups, averaging over all between group pairs) and nonmetric multidimensional scaling (nMDS), both based on Bray-Curtis similarity matrices were used to assess clustering amongst the samples. Both had low stress values (calculated on a scale of $0-1$ ) indicating that the plots were indeed a good representation of the data. Similarity Profile (SimProf) was used as a statistical measure to determine significance to the groupings identified in the Hierarchical clustering at a $5 \%$ significance level.

Similarity percentage (SIMPER) based on the Bray-Curtis similarity matrix was used to determine the OTUs contributing to the top $10 \%$ of differences between the groups. These OTUs were sorted by family and phylum. Relative abundance values for all OTUs within a family or phylum were summed. The total abundance differences between groups for each family were then calculated for each treatment.

\section{COMMUNITY RICHNESS AND DIVERSITY}

Relative richness (measure of the number of different OTUs in a community) was calculated using OTU presence/absence calls from the PhyloChip data. Relative diversity and evenness were calculated using Shannon's diversity and equitability measures, respectively. Evenness is a measure of equality of the community (the relative abundance of the different OTUs present in the community). These calculations were based on the intensity values from the PhyloChip. Because PhyloChip abundance is based on hybridization scores (intensity) relative, not absolute, diversity, and evenness were calculated.

\section{RESULTS}

COLUMN INFLUENT AND EFFLUENT TREATMENT ION DYNAMICS

In order to examine the effect of (per)chlorate on souring in comparison to nitrate in a dynamic sediment system, we monitored the influent and effluent ion concentrations of triplicate up-flow columns for each treatment. Influent nitrate, chlorate, and perchlorate concentrations were kept constant $(\sim 10 \mathrm{mM})$ throughout the study except for a brief period (day 35-38) when the treatment concentration was decreased by $50 \%$ to $5 \mathrm{mM}$ (Figure 1A). Of note, nitrate was never detectable in the effluent from the nitrate treated columns suggesting a rapid adaptation of the microbial community and complete nitrate depletion within the column matrix (Figure 1A). Similarly, chlorate concentrations rapidly dropped in the effluent of the chlorate columns and hovered around $1 \mathrm{mM}$ during the fed batch phase of the study but rapidly decreased to below detection once continuous feeding was established (days 28-51) (Figure 1A). Although (per)chlorate is relatively stable in the presence of sulfide (Gregoire et al., 2014), chlorate is chemically reactive with $\mathrm{Fe}(\mathrm{II})$ according to $\mathrm{ClO}_{3}^{-}+$ $6 \mathrm{Fe}^{2+}+9 \mathrm{H}_{2} \mathrm{O} \rightarrow 6 \mathrm{FeOOH}+\mathrm{Cl}^{-}+12 \mathrm{H}^{+}$(Figure S1). The ferric oxyhydroxide formed $(\mathrm{FeOOH})$ can subsequently be reduced by sulfide according to $6 \mathrm{FeOOH}+3 \mathrm{HS}^{-}+15 \mathrm{H}^{+} \rightarrow 6 \mathrm{Fe}(\mathrm{II})+$ $3 \mathrm{~S}^{\circ}+12 \mathrm{H}_{2} \mathrm{O}$ resulting in redox cycling of the iron as a catalyst and abiotic sulfide oxidation coupled to chlorate reduction. The rapid decrease in effluent chlorate concentrations is probably a combination of both abiotic consumption catalyzed by the $\mathrm{Fe}(\mathrm{II})$ content of the column matrices and microbial community adaptation resulting in microbial chlorate respiration. In contrast to both nitrate and chlorate, perchlorate concentrations remained above $6 \mathrm{mM}$ for the first 17 days of the study and then decreased to below detection by day 21 (Figure 1A). The difference in the rate of chlorate and perchlorate removal is consistent with the chemical stability of perchlorate relative to chlorate even in the presence of $\mathrm{Fe}(\mathrm{II})$ (Figure S1) (Urbansky, 1998, 2002; Urbansky and Brown, 2003) preventing its abiotic removal. As such, its depletion would primarily be driven by microbial adaptation and respiration. As perchlorate is not an abundant electron acceptor in the majority of environments, including the marine sediments from which we obtained our microbial inoculum, (Rajagopalan et al., 2009) slow adaptation of the resident microbial community to perchlorate respiration would be expected.

\section{COLUMN INFLUENT AND EFFLUENT SULFATE AND SULFIDE DYNAMICS}

Throughout operation, some variation in influent sulfate concentrations (19-33 mM) occurred due to tidal mixing with freshwater sources (Sacramento River) at the location of water collection in San Francisco Bay (Figure 1B). In the absence of any column treatment, effluent sulfate concentrations steadily dropped throughout the first 10 days of operation and stabilized at a concentration of $9.64 \pm 1.04 \mathrm{mM}$ (mean $\pm 1 \sigma, n=3$ ) after 11 days, which is equivalent to approximately $40 \%$ removal (Figure 1B, purple line). In support of this sulfide concentrations showed a steady increase from day 10 (Figure 1C, purple line) to a maximum of $21.99 \pm 6.52 \mathrm{mM}$ (mean $\pm 1 \sigma, n=3$ ) by the final day of the study (day 51). During the last 10 days of column operation the average effluent sulfide concentration was $16.44 \pm$ 

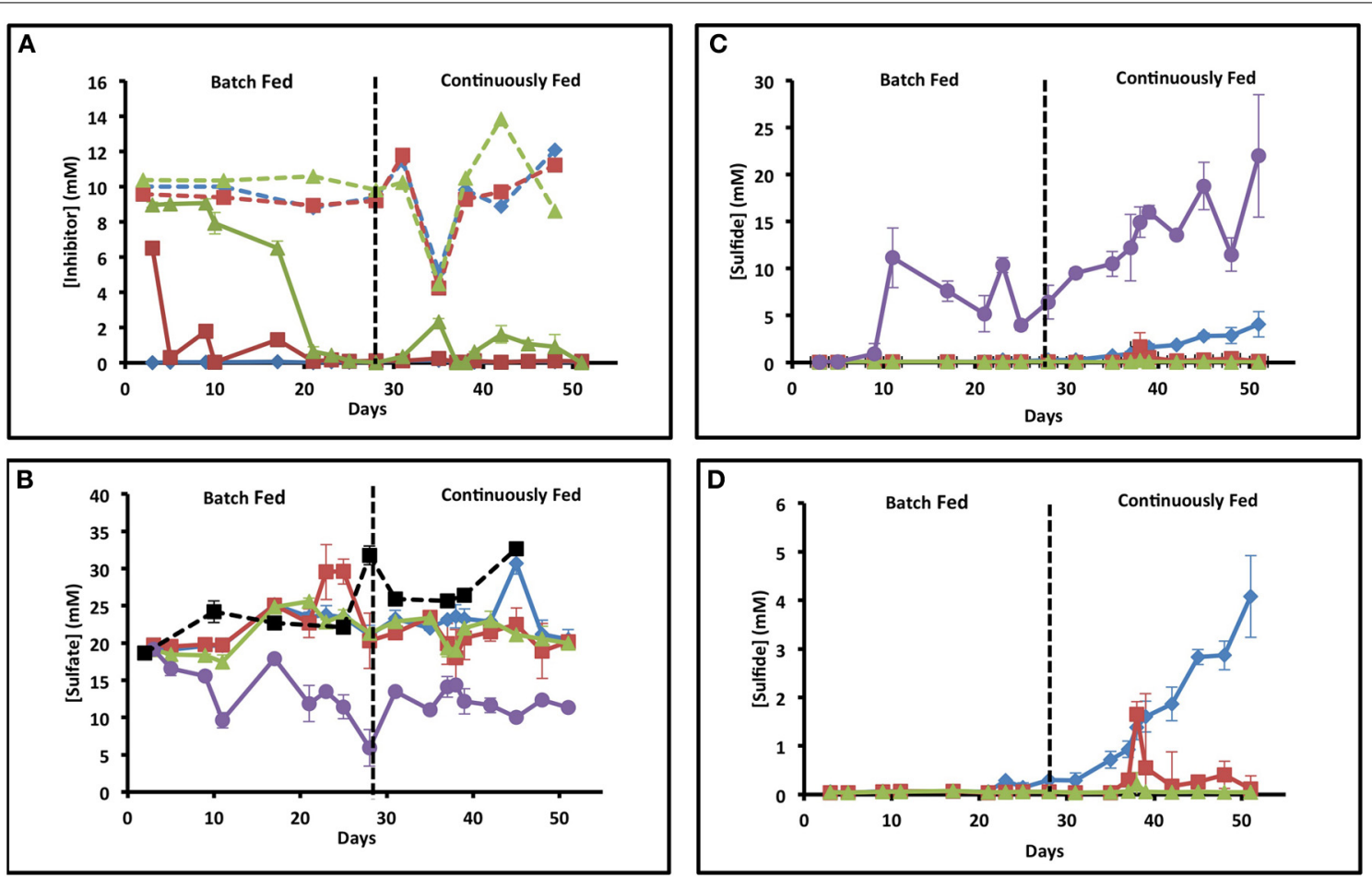

FIGURE 1 | Geochemistry of the influent and effluent of each set of columns. $X$ axis is time in days and $y$ axis is concentration. Error bars represent standard deviation of samples from triplicate columns. Blue diamonds represent samples from nitrate columns, red squares represent samples from chlorate columns, green triangles represent samples from perchlorate columns, and purple circles represent samples from the no

treatment columns. (A) Influent (dashed lines) and effluent (solid lines) concentrations of the three treatments over time. (B) Influent (dashed black line with black squares) and effluent (solid lines) sulfate concentrations over time in days. (C) Effluent concentrations of sulfide over time in all the columns. (D) Blowup of a portion of (C) focusing on just the treated columns.

$4.83 \mathrm{mM}$, which stoichiometrically balanced the sulfate removal $(18.2 \pm 4.55 \mathrm{mM})$ during the same timeframe.

In contrast to the no treatment controls, sulfate concentrations in the effluent of all treated columns showed no significant variation from the influent on a daily basis over the initial 23 days of operation indicating no apparent net sulfate removal (Figure 1B; $t$-test, $p$-value $=0.41)$. In support of this, sulfide concentrations in the effluent remained below detection $(<0.1 \mathrm{mM})$ during this timeframe (Figure 1C). Unexpectedly, although influent nitrate concentrations $(10 \mathrm{mM})$ remained constant, sulfide breakthrough was observed at day 23 in all nitrate columns and measurable sulfide increased steadily to $4.08 \pm 1.36 \mathrm{mM}$ by day 51 (Figure 1D). In contrast, no sulfide breakthrough was observed in the (per)chlorate treated columns except for a short period when the influent treatment concentrations were decreased to $5 \mathrm{mM}$ (from $10 \mathrm{mM}$ ) (day 35-38) (Figure 1D). In this instance sulfide production was transient and peaked at $1.65 \pm 1.53 \mathrm{mM}$ on day 38 for the chlorate columns, and $0.21 \pm 0.24 \mathrm{mM}$ on day 38 for the perchlorate columns (sulfide breakthrough was evident in only one of the three perchlorate columns), decreasing back to below detection by day 39 in both instances.

\section{SULFUR ISOTOPE ANALYSIS}

Sulfur isotope ratios of dissolved sulfate were used to gain further insight into sulfur cycling within the columns. Microbial sulfate reduction results in a well-established shift in the $\delta^{34} \mathrm{~S}$ values of residual sulfate, leading to higher $\delta^{34} S$ values as the fraction of initial sulfate decreases (Kaplan and Rittenberg, 1964; Brüchert, 2004; Brunner and Bernasconi, 2005). In contrast, the sulfide produced has lower $\delta^{34} S$ values than the initial sulfate. The variation in sulfate $\delta^{34} S$ with time was examined for one replicate column of each treatment (Figure 2). It is noteworthy that the influent sulfate had a stable $\delta^{34} S$ value $(20.9 \pm 0.1 \%$, mean $\pm 1 \sigma$, $n=9)$, despite variations in the influent sulfate concentration (Figure 1B) providing a reliable baseline against which effluent $\delta^{34} S$ values were evaluated. In the control columns, effluent sulfate $\delta^{34} \mathrm{~S}$ values rapidly increased to a maximum of $48.8 \%$ on day 28 associated with SRM activity. Effluent sulfate $\delta^{34}$ S values were highly variable before day $28(31.6 \pm 9.3 \%, n=9)$, with high values corresponding to samples taken after periods of noflow alongside a greater extent of sulfate reduction within the columns (Figure 1) and lower values corresponding to flow periods (Figure 2). After day 28, stable $\delta^{34} \mathrm{~S}$ values $(35.0 \pm 1.6 \%$, $n=9$ ) reflect the period of stable continuous flow and a general community $\delta^{34} \mathrm{~S}$ fractionation value.

In contrast to the control columns, the lower extent of sulfate reduction in the treated columns resulted in lower $\delta^{34} \mathrm{~S}$ values (Figure 2). Of note, slight increases in effluent $\delta^{34} S$ above influent values were seen in all treatment columns before measurable sulfide was apparent (Figures 1C, 2) indicating that some 


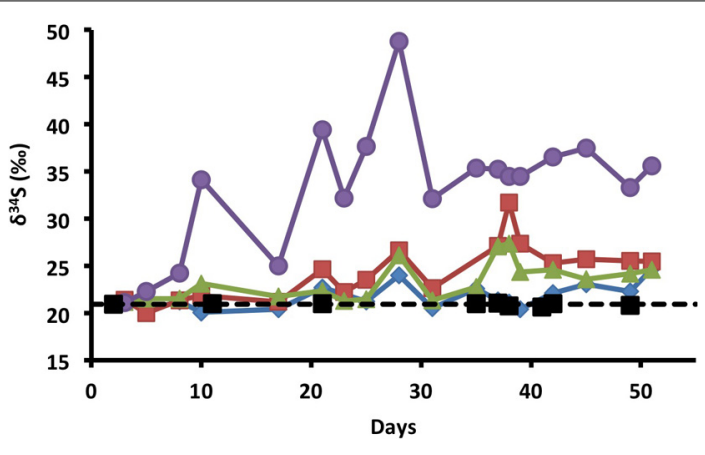

FIGURE 2 | Variation in sulfur isotope ratios of dissolved sulfate with time for influent (black squares and dashed line); and for effluent, nitrate (blue diamonds), chlorate (red squares), perchlorate (green triangles), and no treatment control samples (purple circles).

sulfate reduction occurred even in the presence of the treatment. Visual observations of a blackening of the column matrix, especially in the nitrate columns, suggest that this temporal offset was likely due to reaction of sulfide with iron in the bay sediment, thereby scavenging $\mathrm{H}_{2} \mathrm{~S}$ from solution as iron sulfide precipitates (Morse et al., 1987). A comparison of the nitrate and (per)chlorate columns indicated that although effluent sulfide concentrations were present in the nitrate treatment and absent in the (per)chlorate treatment, effluent sulfate $\delta^{34} \mathrm{~S}$ values were comparable for each of the individual treatments (chlorate $\delta^{34} \mathrm{~S}$ $=24.3 \pm 3.0 \%$; mean $\pm 1 \sigma, n=17$; perchlorate $23.3 \pm 2.0 \%$; $n=18$; nitrate $21.7 \pm 1.3 \% ; n=18$ ). This discrepancy between the (per)chlorate and nitrate treatment is consistent with active redox cycling between sulfide and sulfate in the nitrate columns in which the isotopic sulfate-S signature is masked by the complete microbial oxidation of sulfide to sulfate by sulfur-oxidizing nitrate-reducing bacteria as previously observed (Telang et al., 1997).

\section{COMMUNITY ANALYSES}

PhyloChip (Desantis et al., 2007; Wrighton et al., 2008; Mendes et al., 2011; Handley et al., 2012) microbial community analysis was performed on four replicates of the initial inoculum material and on each triplicate column on four separate temporal samples throughout the study. Sampling dates were chosen that covered the period during which the columns were under continuous flow conditions.

Community changes at the OTU level were investigated by nonparametric Multidimensional Scaling (nMDS) indicated an overall grouping by treatment (Figure 3). In two-dimensional space, the chlorate, nitrate, and no treatment temporal samples all clustered within individual treatment groups at 95\% similarity. In contrast, at this similarity percentile the perchlorate samples grouped into three independent temporal phases (day 31; days 38, and 42; day 51), consistent with an extended adaptation period to perchlorate relative to nitrate or chlorate (Figure 3), an observation supported by the geochemical data (Figure 1A). In the two dimensional representation of the nMDS, two perchlorate samples from day 51 appear to group with some of the no treatment samples at 95\% similarity but in three dimensional space they form an independent group (Figure 3 insert, black arrow). At a $90 \%$ similarity level the perchlorate, chlorate, and no treatment samples all clustered together with the nitrate clustering independently indicating that nitrate had a more drastic effect on the community composition than the perchlorate or chlorate. This is probably due to the rapid outgrowth of a nitrate respiring community relative to a more slowly adapting (per)chlorate respiring community.

Relative diversity and evenness calculations indicated that the perchlorate treatment had the highest relative evenness (Figure S2). The perchlorate samples also had the lowest relative richness based upon presence-absence data. These results suggest that perchlorate had a general uniform effect on the microbial community as a whole and did not stimulate any specific population to a large extent although it may have selective inhibited some members. In contrast, nitrate treatment resulted in the highest relative diversity and the lowest relative evenness (Figure S2). Interestingly, the relative richness was similar to that in the initial and no treatment samples suggesting that nitrate did not have a broad inhibitory effect. Rather, the low evenness suggests that nitrate was in fact a stimulant of some microbial populations pre-existing within the initial community.

To investigate the specific inhibitory and stimulatory impact of the treatments relative to the inoculum, we compared the relative abundance of the top $10 \%$ of the OTUs contributing to the differences between the treated columns, the untreated columns, and the original inoculum. A number of different phyla were enriched or inhibited by the individual treatments compared to the inoculum (Figure S3 and Figures 4A,B). In the absence of any treatment a few families from the phylum Firmicutes and Deltaproteobacteria, specifically the canonical sulfate reducing families Desulfovibrionaceae and Desulfobacteraceae (Figure S3) were stimulated to a small extent relative to the original inoculum. Similarly, several Proteobacterial OTUs decreased with the largest change observed in the Oceanospirillaceae and Vibrionaceae families (Figure S3). In the case of Oceanospirillaceae this is not surprising as these families are composed primarily of aerobic respirers (Garrity et al., 2005) while Vibrionaceae tend to be symbionts of marine animals although there are many free-living species capable of fermentation. Both perchlorate and chlorate had a general inhibitory impact across a broad range of phyla with a minimal stimulatory impact on any individual phylum compared to the inoculum suggesting a broad suppression of microbial activity. Of interest were the differences observed between perchlorate and chlorate treatments, which may be influenced by the disparity in their relative chemical reactivity (Figure S1) (Urbansky, 1998, 2002; Urbansky and Brown, 2003). Various Proteobacteria were of lower relative abundance in perchlorate treatments with the Vibrionaceae being particularly affected (Figure 4A). Other less abundant phyla in perchlorate treatments included Acidobacteria, Verrucomicrobia, Gemmatimonadetes, OP8, Planctomycetes, and WS3. Chlorate affected many, but not all, of the same phyla (Figure 4A).

In contrast to its inhibitory effects, perchlorate enriched for various members of the Firmicutes, Fusobacteria, Proteobacteria (Delta, Gamma, and Epsilon), Verrucomicrobia, Euryarcheota, 


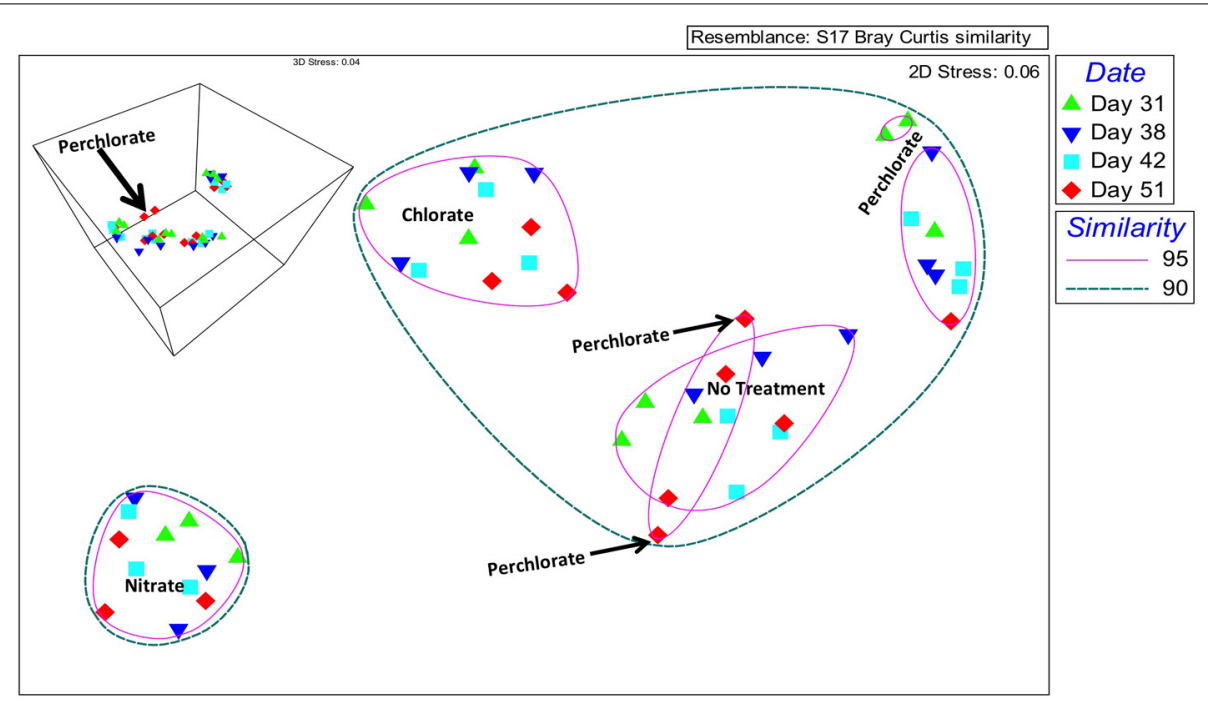

FIGURE 3 | Nonparametric multidimensional scaling of community data based on a Bray-Curtis similarity matrix. Circles represent percent similarity based on hierarchical clustering and colored symbols represent sampling day. The same plot in three dimensions is inset in the upper left hand corner.

and Tenericutes (Figure 4B). Chlorate also enriched for some members of the Proteobacteria (Delta, Gamma, and Epsilon), Firmicutes, Bacteroidetes, and Tenericutes. Curiously, of these various phyla only the Proteobacteria (Alpha, Beta, Gamma, and Epsilon), and Firmicutes have previously described (per)chlorate reducing members with the Betaproteobacteria containing the environmentally dominant perchlorate reducing genera (Dechloromonas and Azospira species) and Gammaproteobacteria containing the majority of the known chlorate reducing species (Pseudomonas) (Coates and Achenbach, 2004). In support of this observation, chlorate treatment specifically stimulated members of the Pseudomonadaceae (Figures 4B, 5B). Interestingly, perchlorate did not enrich for Betaproteobacteria. However, this may be a function of the unsuitability of marine conditions to either the Dechloromonas or Azospira genera, neither of which contain halotolerant isolates (Coates and Achenbach, 2004).

In contrast to both perchlorate and chlorate, while nitrate treatment did have some inhibitory effect on members of the microbial community relative to the inoculum, there was also a strong enrichment of specific phyla (Figures 4A,B). This result supports the conclusions drawn based on the evenness and diversity indices above. Nitrate inhibited members of the Acidobacteria, Gammaproteobacteria, Bacteroidetes, Chloroflexi, Gemmatimonadetes, Planctomycetes, and Verrucomicrobia phyla, while it enriched for Proteobacteria (Alpha, Gamma, and Delta), Firmicutes, and Tenericutes; all of which contain members known to perform nitrate reduction. Nitrate treatment specifically enriched for members of the families Xanthamonadaceae and Pseudomonadaceae within the Gammaproteobacteria. These families contain ubiquitous members known as canonical nitrate reducing organisms (Xanthamonas and Pseudomonas species).

Comparisons were also made between the different treatments (Figures 5A,B). When compared to the no treatment control, all treatments (nitrate, perchlorate, and chlorate) inhibited known sulfate reducing genera supporting the observed geochemical results. Interestingly, both perchlorate and chlorate showed an inhibitory impact on several known sulfate reducing families (Desulfovibrionaceae, Desulfobacteraceae, and Desulfomicrobiaceae), while nitrate only showed inhibition of the Desulfobacteraceae relative to the control reactors (Figure 5A). This result supports the isotopic and geochemical evidence indicating that sulfate reduction occurred in the nitrate-amended columns but was masked by the activity of sulfur oxidizing nitrate reducers.

Both chlorate and nitrate had a stimulatory effect on specific genera (chlorate: Pseudomonadaceae and Pseudoalteromonadaceae; nitrate: Pseudomonadaceae, Xanthamonadaceae, and Rhizobiaceae) relative to the no treatment control (Figure 5A) suggesting that members of these families were responsible for chlorate and nitrate respiration, respectively. In contrast, perchlorate did not result in any obvious stimulatory effect in comparison to the no treatment control and only four families were stimulated to any degree (Desulfuromonadaceae, Desulfobulbaceae, Helicobacteraceae, and Xanthamonadaceae). This result further suggests that community adaptation to perchlorate was slow relative to its inhibitory effect as a whole and diverse growth was not associated with its presence. The result also suggests that members of one or more of the Desulfuromonadaceae, Desulfobulbaceae, and Xanthamonadaceae families have the previously unrecognized ability to respire perchlorate. Helicobacteraceae includes the known perchlorate reducer Wolinella succinogenes. Relative to the chlorate treatment, perchlorate had the greatest inhibitory impact on members of the Deltaproteobacteria and Gammaproteobacteria (Figure 5A). The inhibited Deltaproteobacteria represent the canonical sulfate reducing families Desulfovibrionaceae and Desulfobacteraceae suggesting that perchlorate may be more effective than chlorate as an inhibitor of the SRM in the community. A similar comparison 


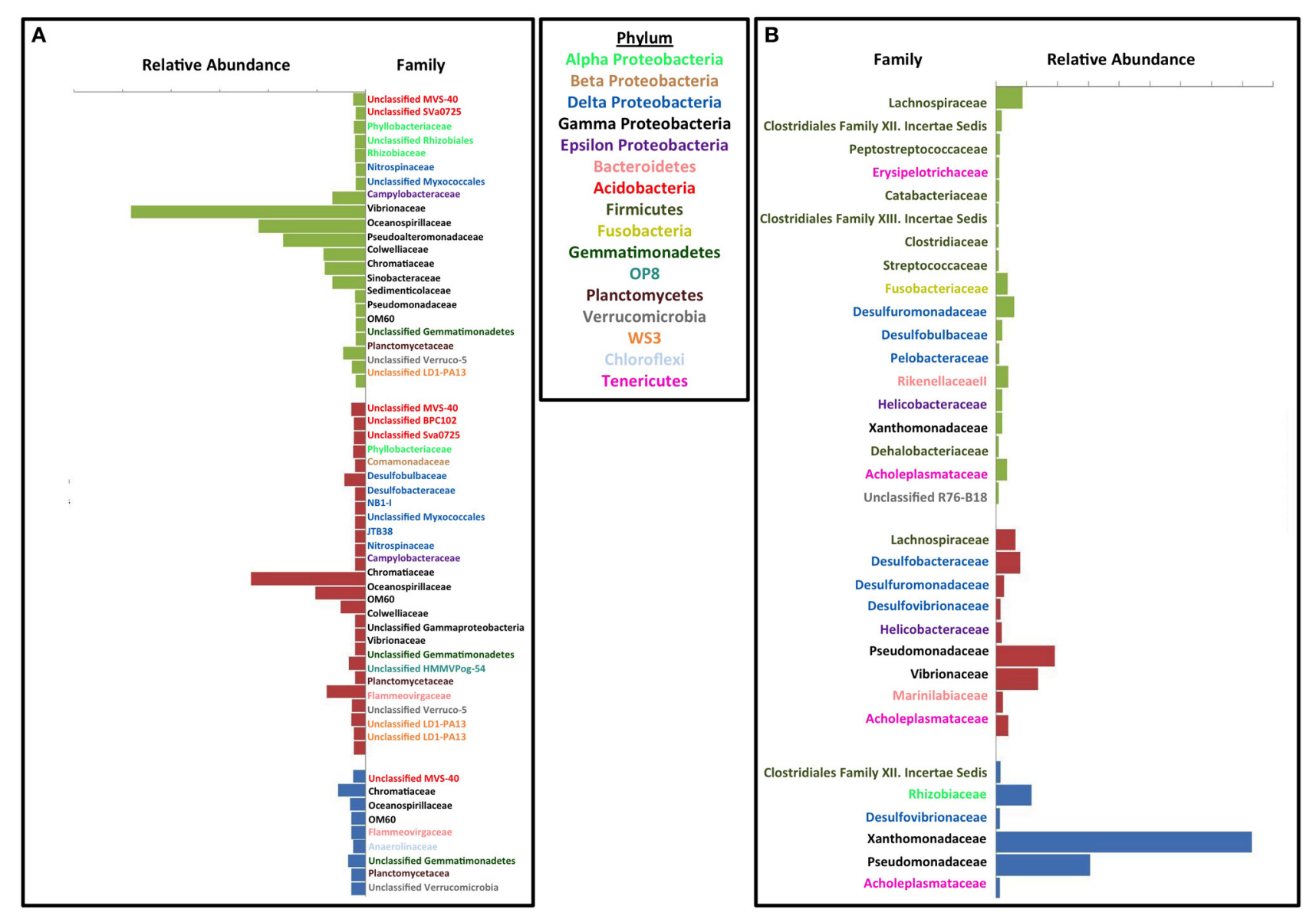

FIGURE 4 | Effect of each treatment on microbial community compared to the initial innoculum. Similarity percentage (SIMPER) was used to determine the OTUs that contribute to the top $10 \%$ of difference between each set of treatment samples and the initial inoculum samples. Average abundance for the OTUs belonging to the same family were added together. Abundance on the $\mathrm{x}$ axis is the difference between average abundance for samples from the corresponding treatment and the initial inoculum samples. Each plot is labeled by family on the $y$ axis and the family names are color coded by phylum. Green bars represent perchlorate treated columns, red bars represent chlorate treated columns, and blue bars represent nitrate treated columns. (A) Inhibitory effects of each treatment. (B) Enrichment effect due to each treatment. with nitrate also indicated that perchlorate showed a greater inhibition of members of the Desulfovibrionaceae, a result that is supported by geochemical evidence (Figure 1C). The inhibition of Gammaproteobacteria by perchlorate relative to chlorate may be explained by the selective enrichment in this phylum by chlorate treatment relative to the perchlorate treatment and the no treatment control (Figure 5B).

\section{DISCUSSION}

Our study clearly demonstrates that both perchlorate and chlorate are effective inhibitors of microbial sulfate reduction in a marine system. This conclusion is drawn from geochemical, isotopic, and 16S rRNA community data analysis. In the absence of any treatment, rapid and extensive sulfate reduction was observed in flow through column systems. However, the presence of either perchlorate or chlorate effectively constrained sulfide production.

In the case of nitrate treatment, although sulfide production was initially attenuated, nitrate was completely consumed in the columns and measurable sulfide reappeared 23 days into the study suggesting that microbial community succession was occurring as previously observed (Voordouw et al., 1996; Myhr et al., 2002; Bødtker et al., 2008, 2009; Hubert, 2010; Callbeck et al., 2011). Both the stable isotope and community analyses support this result and suggest that the true extent of SRM activity was masked through the activity of nitrate-dependent sulfur oxidizing (NDSO) microorganisms as previously suggested (Telang et al., 1997; Greene et al., 2003; Hubert et al., 2009; Hubert, 2010). Complete conversion of sulfide to sulfate by NDSO activity allows for sulfur cycling to occur between sulfide and sulfate species which can maintain active SRM populations in the presence of nitrate, especially if the organisms are resistant to nitrite that may be produced as a transient intermediate of nitrate respiration (Greene et al., 2003; He et al., 2010). In electron donor rich systems such as oil reservoirs, which are often replete with biologically labile organic acids (Vance and Thrasher, 2005) and hydrocarbons that many SRM are capable of utilizing (Aeckersberg et al., 1991; Beller et al., 1992, 1996; Edwards et al., 1992; Widdel et al., 1992; Lovley et al., 1995; Coates et al., 1996a,b, 


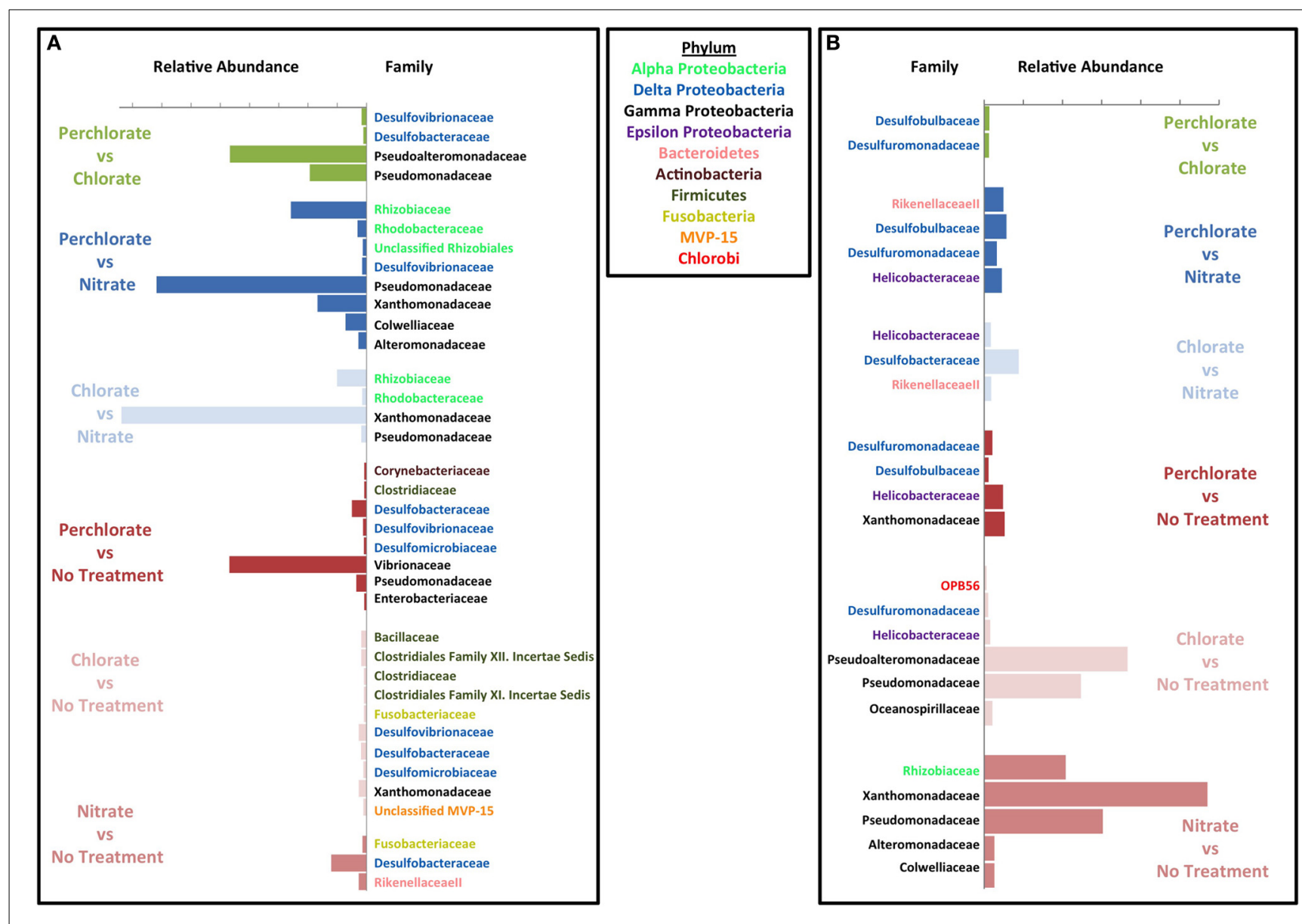

FIGURE 5 | Effect of each treatment on microbial community compared to the other treatments. Similarity percentage (SIMPER) was used to determine the OTUs that contribute to the top $10 \%$ of difference between each set of treatment samples and the initial innoculum samples. Average abundance for the OTUs belonging to the same family were added together. Abundance on the $x$ axis is the difference between average abundance for samples from the corresponding treatment and the initial innoculum samples. Each plot is labeled by family on the $y$ axis and the family names are color coded by phylum. Green bars represent comparison between perchlorate and chlorate treated columns, blue bars represent comparisons against nitrate treated columns (with the perchlorate vs. nitrate in dark blue and chlorate vs. nitrate in light blue), and red bars represent comparisons against untreated columns (Perchlorate vs. no treatment in dark red, chlorate vs. no treatment in light red and nitrate vs. no treatment in medium red). (A) Inhibitory effects. (B) Enrichment effects.
1997; Bedessem et al., 1997; Caldwell et al., 1998; Galushko et al., 1999; Anderson and Lovley, 2000; Annweiler et al., 2000; Abu Laban et al., 2009), such sulfur redox cycling combined with heterotrophic nitrate reduction can lead to a more rapid depletion of the nitrate with the resultant onset of uninhibited sulfate reduction deeper in a reservoir (Callbeck et al., 2011). Furthermore, as some SRM are alternatively capable of utilizing nitrate as a suitable electron acceptor (Keith and Herbert, 1983; Dalsgaard and Bak, 1994; Moura et al., 1997, 2007; López-Cortés et al., 2006; Marietou et al., 2009), nitrate addition may in fact enhance population size rather than limiting it resulting in a robust SRM community that can generate large amounts of sulfide if nitrate injection is interrupted, such as during reservoir shut-in periods. No SRM have been isolated to date that can grow by respiratory perchlorate reduction, though some evidence exists that at high temperatures a cryptic mixed biotic-abiotic perchlorate reduction process can be catalyzed by thermophilic sulfate reducers (Liebensteiner et al., 2013).
In contrast to the nitrate and control columns, no sulfide was detected in effluent from either the perchlorate or chlorate columns unless the treatment concentration was dropped to $5 \mathrm{mM}$. Even in this instance, sulfide production was immediately eradicated on reestablishment of the treatment concentration suggesting a concentration threshold may exist. The nature of this threshold concentration is likely to be a function of the inhibitory effect of (per)chlorate on microbial sub-populations and the preferential thermodynamics of (per)chlorate respiration.

The sulfur isotope data showed greater evidence of dynamic sulfur cycling than was evident from the fluid chemistry alone. The combination of low $\delta^{34} \mathrm{~S}$ sulfate values and elevated sulfide in the nitrate treatment is consistent with active sulfur redox cycling in the nitrate columns in which the $\delta^{34} \mathrm{~S}$ isotopic signature of sulfate reduction is (partially) masked by the microbial oxidation of sulfide to sulfate by NDSO microorganisms as previously observed (Hubert et al., 2009). This is because, in comparison with microbial sulfate reduction, microbial sulfide 
oxidation often produces little sulfur isotope fractionation (Toran and Harris, 1989; Hubert et al., 2009; Brabec et al., 2012). As such, the sulfate produced retains low $\delta^{34} S$ values similar to the sulfide, thus the net sulfate in the effluent is a combination of the heavy residual sulfate from sulfate reduction (high $\delta^{34} S$ values) and the light biogenic sulfate from sulfide oxidation (low $\delta^{34} S$ values). Ultimately, in a nitrate treated column, effluent sulfate $\delta^{34} S$ will depend on the relative importance of the biocompetitive exclusion mechanism and the sulfide re-oxidation pathway, as seen previously by Hubert et al. (2009). In comparison, although DPRB oxidize sulfide innately, the end product of this metabolism is generally insoluble elemental sulfur (Gregoire et al., 2014) which would remove sulfide from the system without affecting the $\delta^{34} S$ values of the residual sulfate in the effluent. The sulfur isotope data also (Figure 2) suggested that even when sulfide was not detected in the column effluent, some residual sulfate reduction was occurring in the treated columns, demonstrating that the $\delta^{34} S$ of effluent sulfate in oil reservoir production waters could potentially provide an effective early indication of souring before breakthrough of the $\mathrm{H}_{2} \mathrm{~S}$ front in reservoirs where the rock matrix has significant $\mathrm{H}_{2} \mathrm{~S}$ scavenging potential.

Our microbial community data illustrated that each treatment had a distinct impact on the overall microbial community. Nitrate treatment caused the most dramatic shift in community composition as assessed by nMDS analysis and hierarchical clustering. This is not surprising because complete nitrate reduction to ammonia or dinitrogen involves multiple genes (nir, nos, nrf) that are present in a broad diversity of bacterial phylotypes in mixed microbial ecosystems (Moreno-Vivián et al., 1999). Thus, nitrate addition is expected to stimulate a mixture of bacterial families from across the phylogenetic tree.

Deltaproteobacteria are an important component of the microbial communities in this study. The Deltaproteobacteria include both SRMs and non-SRMs. The SRMs fall into various families including Desulfovibrionaceae, Desulfobulbaceae, Desulfomicrobiaceae, and Desulfobacteriaceae. Elemental sulfur $\left(S^{0}\right)$ reducing members of this class include Desulfurellaceae, Pelobacteraceae, and Desulfuromonadaceae (Castro et al., 2000; Friedrich et al., 2001). Desulfobulbaceae species have also been shown to be capable of growing by sulfur oxidation (Pfeffer et al., 2012). Although Callbeck et al. (2011) showed Desulfobulbus (family Desulfobulbaceae) to be primarily SRMs, in our reactors they may act as elemental sulfur reducers or sulfide oxidizers because members of this family are primarily enriched in treated columns where no net sulfide production is observed. Obligately $\mathrm{S}^{0}$ reducing families (Desulfuromonadaceae) are also enriched in (per)chlorate treatments vs. both nitrate treatment and the no treatment controls. Based on known metabolic capabilities of members of the Desulfobulbaceae (sulfate reduction, $S^{o}$ disproportionation, and autotrophic $\mathrm{H}_{2} \mathrm{~S}$ oxidation) and the Desulfuromonadaceae, the enrichment of these organisms may involve the redox cycling of sulfur between $\mathrm{H}_{2} \mathrm{~S}$ and elemental sulfur which supports earlier studies demonstrating that all DPRB innately oxidize $\mathrm{H}_{2} \mathrm{~S}$ to elemental sulfur (Gregoire et al., 2014). In support of a central role of elemental sulfur in these reactors, (per)chlorate treatments also enriched for Helicobacteraceae which includes members of the genera Flexispira, Sulfurimonas, Sulfurovum, and Sulfuricurvum, all of which are known to oxidize sulfur and all of which were enriched by perchlorate (Inagaki et al., 2003, 2004; Kodama and Watanabe, 2004; Takai et al., 2006). Isolated perchlorate reducing bacteria all belong to the Proteobacteria (Alpha, Beta, Gamma, and Epsilon) and Firmicutes. All isolated chlorate-reducing bacteria are Proteobacteria (Beta, and Gamma). However, all perchlorate reducing organisms can also reduce chlorate (Coates and Achenbach, 2004) and evidence indicates the ability to respire both perchlorate and chlorate has been spread by horizontal gene transfer (Coates and Achenbach, 2004; Melnyk et al., 2011, 2014; Clark et al., 2013) suggesting that the diversity of organisms capable of these metabolisms may be far more extensive than current isolates suggest. This may explain why (per)chlorate treatment enriches for a variety of Firmicutes, Fusobacteria, Gammaproteobacteria, Bacteroidetes, and Epsilonproteobacteria.

Despite the fact that no sulfide was measured in the effluent from the (per)chlorate columns both the isotopic measurements and community analysis support the fact that (per)chlorate indeed stimulates sulfur cycling in the column system. (Per)chlorate treatment enriches for organisms known to be capable of sulfide oxidation, $S^{0}$ oxidation, $S^{0}$ disproportion, and $S^{0}$ reduction; and results in a decrease in the abundance of canonical SRM. This supports a model in which perchlorate both directly inhibits sulfate reduction and stimulates sulfur cycling. Nitrate is not only less effective at preventing souring in this system, but it also doesn't appear to stimulate the same sort of sulfur cycling that is seen in the (per)chlorate columns.

Taken together our findings indicate that (per)chlorate and nitrate are mechanistically distinct inhibitors of sulfide production in complex natural ecosystems. The apparently greater inhibitory potency of (per)chlorate relative to nitrate and potentially favorable shifts in geochemistry and microbial communities suggest that (per)chlorate may be a promising alternative to nitrate for controlling bio-souring in industrial ecosystems. Currently, the potential for perchlorate respiration in an oil reservoir is unknown. Future studies are needed to investigate the application of perchlorate with sulfidogenic samples from industrial ecosystems including oil reservoirs using crude oil or produced water organic components as the electron donor(s).

\section{ACKNOWLEDGMENTS}

The authors would like to acknowledge the Energy Biosciences Institute (EBI) for funding this work. Additionally we would like to acknowledge Jay Patel and Yasmin Peled for experimental help, and Wenbo Yang for sulfur isotope analysis.

\section{SUPPLEMENTARY MATERIAL}

The Supplementary Material for this article can be found online at: http://www.frontiersin.org/journal/10.3389/fmicb. 2014.00315/abstract

\section{REFERENCES}

Abu Laban, N., Selesi, D., Jobelius, C., and Meckenstock, R. U. (2009). Anaerobic benzene degradation by Gram-positive sulfate-reducing bacteria. FEMS Microbiol. Ecol. 68, 300-311. doi: 10.1111/j.1574-6941.2009. 00672.x

Aeckersberg, F., Bak, F., and Widdel, F. (1991). Anaerobic oxidation of saturated hydrocarbons to $\mathrm{CO} 2$ by a new type of sulfate-reducing bacterium. Arch. Microbiol. 156, 5-14. doi: 10.1007/BF00418180 
Anderson, R. T., and Lovley, D. R. (2000). Anaerobic bioremediation of benzene under sulfate-reducing conditions in a petroleum-contaminated aquifer. Environ. Sci. Technol. 34, 2261-2266. doi: 10.1021/es991211a

Annweiler, E., Materna, A., Safinowski, M., Kappler, A., Richnow, H. H., Michaelis, W., et al. (2000). Anaerobic degradation of 2-methylnaphthalene by a sulfatereducing enrichment culture. Appl. Environ. Microbiol. 66, 5329-5333. doi: 10.1128/AEM.66.12.5329-5333.2000

Baeuerle, P. A., and Huttner, W. B. (1986). Chlorate-a potent inhibitor of protein sulfation in intact cells. Biochem. Biophys. Res. Commun. 141, 870-877. doi: 10.1016/S0006-291X(86)80253-4

Bedessem, M. E., Swoboda-Colberg, N. G., and Colberg, P. J. S. (1997). Naphthalene mineralization coupled to sulfate reduction in aquifer-derived enrichments. FEMS Microbiol. Lett. 152, 213-218. doi: 10.1111/j.15746968.1997.tb10430.x

Beller, H. R., Grbic-Galic, D., and Reinhard, M. (1992). Microbial degradation of toluene under sulfate-reducing conditions and the influence of iron on the process. Appl. Environ. Microbiol. 58, 786-793.

Beller, H. R., Spormann, A. M., Sharma, P. K., Cole, J. R., and Reinhard, M. (1996). Isolation and characterization of a novel toluene-degrading, sulfate-reducing bacterium. Appl. Environ. Microbiol. 62, 1188-1196.

Bødtker, G., Lysnes, K., Torsvik, T., Bjørnestad, E. Ø., and Sunde, E. (2009). Microbial analysis of backflowed injection water from a nitrate-treated North Sea oil reservoir. J. Ind. Microbiol. Biotechnol. 36, 439-450. doi: 10.1007/s10295008-0515-6

Bødtker, G., Thorstenson, T., Lillebø, B.-L. P., Thorbjørnsen, B. E., Ulvøen, R. H., Sunde, E., et al. (2008). The effect of long-term nitrate treatment on SRB activity, corrosion rate and bacterial community composition in offshore water injection systems. J. Ind. Microbiol. Biotechnol. 35, 1625-1636. doi: 10.1007/s10295-008-0406-X

Brabec, M. Y., Lyons, T. W., and Mandernack, K. W. (2012). Oxygen and sulfur isotope fractionation during sulfide oxidation by anoxygenic phototrophic bacteria. Geochim. Cosmochim. Acta 83, 234-251. doi: 10.1016/j.gca.2011.12.008

Bruce, R. A., Achenbach, L. A., and Coates, J. D. (1999). Reduction of (per)chlorate by a novel organism isolated from paper mill waste. Environ. Microbiol. 1, 319-329. doi: 10.1046/j.1462-2920.1999.00042.x

Brüchert, V. (2004). "Physiological and ecological aspects of sulfur isotope fractionation during bacterial sulfate reduction," in Sulfur Biogeochemistry-Past and Present: Geological Society of America Special Paper 379, eds J. P. Amend, K. J. Edwards, and T. W. Lyons, 1-16.

Brunner, B., and Bernasconi, S. M. (2005). A revised isotope fractionation model for dissimilatory sulfate reduction in sulfate reducing bacteria. Geochim. Cosmochim. Acta 69, 4759-4771. doi: 10.1016/j.gca.2005.04.015

Caldwell, M. E., Garrett, R. M., Prince, R. C., and Suflita, J. M. (1998). Anaerobic biodegradation of long-chain n-alkanes under sulfate-reducing conditions. Environ. Sci. Technol. 32, 2191-2195. doi: 10.1021/es9801083

Callbeck, C., Dong, X., Chatterjee, I., Agrawal, A., Caffrey, S., Sensen, C., et al. (2011). Microbial community succession in a bioreactor modeling a souring low-temperature oil reservoir subjected to nitrate injection. Appl. Microbiol. Biotechnol. 91, 799-810. doi: 10.1007/s00253-011-3287-2

Callbeck, C. M., Agrawal, A., and Voordouw, G. (2013). Acetate production from oil under sulfate-reducing conditions in bioreactors injected with sulfate and nitrate. Appl. Environ. Microbiol. 79, 5059-5068. doi: 10.1128/AEM.01251-13

Castro, H. F., Williams, N. H., and Ogram, A. (2000). Phylogeny of sulfate-reducing bacteria(1). FEMS Microbiol. Ecol. 31, 1-9.

Christensen, T. H., Bjerg, P. L., Banwart, S. A., Jakobsen, R., Heron, G., and Albrechtsen, H.-J. (2000). Characterization of redox conditions in groundwater contaminant plumes. J. Con. Hydrol. 45, 165-241. doi: 10.1016/S01697722(00)00109-1

Clark, I. C., Melnyk, R. A., Engelbrektson, A., and Coates, J. D. (2013). Structure and evolution of chlorate reduction composite transposons. MBio 4, e00379-e00313. doi: 10.1128/mBio.00379-13

Cline, J. D. (1969). Spectrophotometric determination of hydrogen sulfide in natural waters. Limnol. Oceanogr. 14, 454-458. doi: 10.4319/lo.1969.14.3.0454

Coates, J. D., and Achenbach, L. A. (2004). Microbial perchlorate reduction: rocketfuelled metabolism. Nat. Rev. Microbiol. 2, 569-580. doi: 10.1038/nrmicro926

Coates, J. D., Anderson, R. T., and Lovley, D. R. (1996a). Oxidation of polycyclic aromatic hydrocarbons under sulfate-reducing conditions. Appl. Environ. Microbiol. 62, 1099-1101.

Coates, J. D., Anderson, R. T., Woodward, J. C., Phillips, E. J. P., and Lovley, D. R. (1996b). Anaerobic hydrocarbon degradation in petroleum-contaminated harbor sediments under sulfate-reducing and artificially imposed iron-reducing conditions. Environ. Sci. Technol. 30, 2784-2789. doi: 10.1021/es9600441

Coates, J. D., Chakraborty, R., Lack, J. G., O'Connor, S. M., Cole, K. A., Bender, K. S., et al. (2001). Anaerobic benzene oxidation coupled to nitrate reduction in pure culture by two strains of Dechloromonas. Nature 411, 1039-1043. doi: $10.1038 / 35082545$

Coates, J. D., Michaelidou, U., Bruce, R. A., O’Connor, S. M., Crespi, J. N., and Achenbach, L. A. (1999). Ubiquity and diversity of dissimilatory (per) chloratereducing bacteria. Appl. Environ. Microbiol. 65, 5234-5241.

Coates, J. D., Woodward, J., Allen, J., Philp, P., and Lovley, D. R. (1997). Anaerobic degradation of polycyclic aromatic hydrocarbons and alkanes in petroleum-contaminated marine harbor sediments. Appl. Environ. Microbiol. 63, 3589-3593.

Dalsgaard, T., and Bak, F. (1994). Nitrate reduction in a sulfate-reducing bacterium, Desulfovibrio desulfuricans, isolated from rice paddy soil: sulfide inhibition, kinetics, and regulation. Appl. Environ. Microbiol. 60, 291-297.

Desantis, T. Z., Brodie, E. L., Moberg, J. P., Zubieta, I. X., Piceno, Y. M., and Andersen, G. L. (2007). High-density universal 16S rRNA microarray analysis reveals broader diversity than typical clone library when sampling the environment. Microb. Ecol. 53, 371-383. doi: 10.1007/s00248-006-9134-9

Edwards, E. A., Wills, L. E., Reinhard, M., and Grbic-Galic, D. (1992). Anaerobic degradation of toluene and xylene by aquifer microorganisms under sulfatereducing conditions. Appl. Environ. Microbiol. 58, 794-800.

Friedrich, C. G., Rother, D., Bardischewsky, F., Quentmeier, A., and Fischer, J. (2001). Oxidation of reduced inorganic sulfur compounds by bacteria: emergence of a common mechanism? Appl. Environ. Microbiol. 67, 2873-2882. doi: 10.1128/AEM.67.7.2873-2882.2001

Fuller, D. C., and Suruda, A. J. (2000). Occupationally related hydrogen sulfide deaths in the United States from 1984 to 1994. J. Occup. Environ. Med. 42, 939-942. doi: 10.1097/00043764-200009000-00019

Galushko, A., Minz, D., Schink, B., and Widdel, F. (1999). Anaerobic degradation of naphthalene by a pure culture of a novel type of marine sulphate-reducing bacterium. Environ. Microbiol. 1, 415-420. doi: 10.1046/j.1462-2920.1999.00051.x

Garrity, G. M., Bell, J. A., and Lilburn, T. (2005). "Family I. Oceanospirillaceae fam. nov.", in Bergey's Manual of Systematic Bacteriology, 2nd Edn., Vol. 2 (The Proteobacteria), Part B (The Gammaproteobacteria), eds D. J. Brenner, N. R. Krieg, J. T. Staley, and G. M. Garrity (New York, NY: Springer), 271.

Gevertz, D., Telang, A. J., Voordouw, G., and Jenneman, G. E. (2000). Isolation and characterization of strains CVO and FWKO B, two novel nitrate-reducing, sulfide-oxidizing bacteria isolated from oil field brine. Appl. Environ. Microbiol. 66, 2491-2501. doi: 10.1128/AEM.66.6.2491-2501.2000

Gieg, L., Jack, T., and Foght, J. (2011). Biological souring and mitigation in oil reservoirs. Appl. Microbiol. Biotechnol. 92, 263-282. doi: 10.1007/s00253-0113542-6

Greene, E., Hubert, C., Nemati, M., Jenneman, G., and Voordouw, G. (2003). Nitrite reductase activity of sulphate-reducing bacteria prevents their inhibition by nitrate-reducing, sulphide-oxidizing bacteria. Environ. Microbiol. 5, 607-617. doi: 10.1046/j.1462-2920.2003.00446.x

Gregoire, P., Engelbrektson, A., Hubbard, C. G., Metlagel, Z., Csencsits, R., Auer, M., et al. (2014). Control of sulfidogenesis through bio-oxidation of H2S coupled to (per)chlorate reduction. Environ. Microbiol. Rep. doi: 10.1111/17582229.12156. [Epub ahead of print].

Handley, K. M., Wrighton, K. C., Piceno, Y. M., Andersen, G. L., Desantis, T. Z., Williams, K. H., et al. (2012). High-density PhyloChip profiling of stimulated aquifer microbial communities reveals a complex response to acetate amendment. FEMS Microbiol. Ecol. 81, 188-204. doi: 10.1111/j.15746941.2012.01363.x

He, Q., He, Z., Joyner, D. C., Joachimiak, M., Price, M. N., Yang, Z. K., et al. (2010). Impact of elevated nitrate on sulfate-reducing bacteria: a comparative study of Desulfovibrio vulgaris. ISME J. 4, 1386-1397. doi: 10.1038/ismej.2010.59

Hubert, C. (2010). "Microbial ecology of oil reservoir souring and its control by nitrate injection," in Handbook of Hydrocarbon and Lipid Microbiology, ed K. Timmis (Berlin; Heidelberg: Springer), 2753-2766.

Hubert, C., Voordouw, G., and Mayer, B. (2009). Elucidating microbial processes in nitrate- and sulfate-reducing systems using sulfur and oxygen isotope ratios: the example of oil reservoir souring control. Geochim. Cosmochim. Acta 73, 3864-3879. doi: 10.1016/j.gca.2009.03.025

Inagaki, F., Takai, K., Kobayashi, H., Nealson, K. H., and Horikoshi, K. (2003). Sulfurimonas autotrophica gen. nov., sp. nov., a novel sulfur-oxidizing $\varepsilon$-proteobacterium isolated from hydrothermal sediments in the Mid-Okinawa 
Trough. Int. J. Syst. Evol. Microbiol. 53, 1801-1805. doi: 10.1099/ijs.0. 02682-0

Inagaki, F., Takai, K., Nealson, K. H., and Horikoshi, K. (2004). Sulfurovum lithotrophicum gen. nov., sp. nov., a novel sulfur-oxidizing chemolithoautotroph within the $\varepsilon$-Proteobacteria isolated from Okinawa Trough hydrothermal sediments. Int. J. Syst. Evol. Microbiol. 54, 1477-1482. doi: 10.1099/ijs.0.03042-0

Kaplan, I., and Rittenberg, S. (1964). Microbiological fractionation of sulphur isotopes. J. Gen. Microbiol. 34, 195-212. doi: 10.1099/00221287-34-2-195

Keith, S., and Herbert, R. (1983). Dissimilatory nitrate reduction by a strain of Desulfovibrio desulfuricans. FEMS Microbiol. Lett. 18, 55-59. doi: 10.1111/j.1574-6968.1983.tb00448.x

Kodama, Y., and Watanabe, K. (2004). Sulfuricurvum kujiense gen. nov., sp. nov., a facultatively anaerobic, chemolithoautotrophic, sulfur-oxidizing bacterium isolated from an underground crude-oil storage cavity. Int. J. Syst. Evol. Microbiol. 54, 2297-2300. doi: 10.1099/ijs.0.63243-0

Liebensteiner, M. G., Pinkse, M. W., Schaap, P. J., Stams, A. J., and Lomans, B. P. (2013). Archaeal (per) chlorate reduction at high temperature: an interplay of biotic and abiotic reactions. Science 340, 85-87. doi: 10.1126/science.1233957

López-Cortés, A., Fardeau, M.-L., Fauque, G., Joulian, C., and Ollivier, B. (2006). Reclassification of the sulfate- and nitrate-reducing bacterium Desulfovibrio vulgaris subsp. oxamicus as Desulfovibrio oxamicus sp. nov., comb. nov. Int. J. Syst. Evol. Microbiol. 56, 1495-1499. doi: 10.1099/ijs.0.64074-0

Lovley, D. R., and Chapelle, F. H. (1995). Deep subsurface microbial processes. Rev. Geophys. 33, 365-381. doi: 10.1029/95RG01305

Lovley, D. R., Coates, J. D., Woodward, J. C., and Phillips, E. (1995). Benzene oxidation coupled to sulfate reduction. Appl. Environ. Microbiol. 61, 953-958.

Lovley, D. R., and Goodwin, S. (1988). Hydrogen concentrations as an indicator of the predominant terminal electron accepting reactions in aquatic sediments. Geochim. Cosmochim. Acta 52, 2993-3003. doi: 10.1016/0016-7037(88)90163-9

Marietou, A., Griffiths, L., and Cole, J. (2009). Preferential reduction of the thermodynamically less favorable electron acceptor, sulfate, by a nitrate-reducing strain of the sulfate-reducing bacterium Desulfovibrio desulfuricans 27774. J. Bacteriol. 191, 882-889. doi: 10.1128/JB.01171-08

Melnyk, R. A., Clark, I. C., Liao, A., and Coates, J. D. (2014). Transposon and deletion mutagenesis of genes involved in perchlorate reduction in Azospira suillum PS. MBio 5, e00769-e00713. doi: 10.1128/mBio.00769-13

Melnyk, R. A., Engelbrektson, A., Clark, I. C., Carlson, H. K., Byrne-Bailey, K., and Coates, J. D. (2011). Identification of a perchlorate reduction genomic island with novel regulatory and metabolic genes. Appl. Environ. Microbiol. 77, 7401-7404. doi: 10.1128/AEM.05758-11

Mendes, R., Kruijt, M., de Bruijn, I., Dekkers, E., van der Voort, M., Schneider, J. H., et al. (2011). Deciphering the rhizosphere microbiome for disease-suppressive bacteria. Science 332, 1097-1100. doi: 10.1126/science.1203980

Moreno-Vivián, C., Cabello, P., Martínez-Luque, M., Blasco, R., and Castillo, F. (1999). Prokaryotic nitrate reduction: molecular properties and functional distinction among bacterial nitrate reductases. J. Bact. 181, 6573-6584.

Morse, J. W., Millero, F. J., Cornwell, J. C., and Rickard, D. (1987). The chemistry of the hydrogen sulfide and iron sulfide systems in natural waters. Earth-Sci. Rev. 24, 1-42. doi: 10.1016/0012-8252(87)90046-8

Moura, I., Bursakov, S., Costa, C., and Moura, J. J. (1997). Nitrate and nitrite utilization in sulfate-reducing bacteria. Anaerobe 3, 279-290. doi: 10.1006/anae.1997.0093

Moura, J. J., Gonzalez, P., Moura, I., and Fauque, G. (2007). Dissimilatory nitrate and nitrite ammonification by sulphate-reducing eubacteria. Sulphate-reducing bacteria. Environ. Eng. Syst. 241-264. doi: 10.1017/CBO9780511541490.009

Myhr, S., Lillebø, B. L., Sunde, E., Beeder, J., and Torsvik, T. (2002). Inhibition of microbial $\mathrm{H}_{2} \mathrm{~S}$ production in an oil reservoir model column by nitrate injection. Appl. Microbiol. Biotechnol. 58, 400-408. doi: 10.1007/s00253-001-0881-8

Pfeffer, C., Larsen, S., Song, J., Dong, M., Besenbacher, F., Meyer, R. L., et al. (2012). Filamentous bacteria transport electrons over centimetre distances. Nature 491, 218-221. doi: 10.1038/nature11586

Postgate, J. R. (1952). Competitive and non-competitive inhibitors of bacterial sulphate reduction. J. Gen. Microbiol. 6, 128-142. doi: 10.1099/00221287-6-12-128

Rabus, R., and Heider, J. (1998). Initial reactions of anaerobic metabolism of alkylbenzenes in denitrifying and sulfate-reducing bacteria. Arch. Microbiol. 170, 377-384. doi: 10.1007/s002030050656

Rajagopalan, S., Anderson, T., Cox, S., Harvey, G., Cheng, Q., and Jackson, W. A. (2009). Perchlorate in wet deposition across North America. Environ. Sci. Technol. 43, 616-622. doi: 10.1021/es801737u
Sunde, E., and Torsvik, T. (2005). "Microbial control of hydrogen sulfide production in oil reservoirs," in Petroleum microbiology, eds B. Ollivier and M. Magot (Washington, DC: ASM Press), 201-213.

Takai, K., Suzuki, M., Nakagawa, S., Miyazaki, M., Suzuki, Y., Inagaki, F., et al. (2006). Sulfurimonas paralvinellae sp. nov., a novel mesophilic, hydrogenand sulfur-oxidizing chemolithoautotroph within the Epsilonproteobacteria isolated from a deep-sea hydrothermal vent polychaete nest, reclassification of Thiomicrospira denitrificans as Sulfurimonas denitrificans comb. nov. and emended description of the genus Sulfurimonas. Int. J. Syst. Evol. Microbiol. 56, 1725-1733. doi: 10.1099/ijs.0.64255-0

Telang, A. J., Ebert, S., Foght, J. M., Westlake, D. W. S., Jenneman, G. E., Gevertz, D., et al. (1997). Effect of nitrate injection on the microbial community in an oil field as monitored by reverse sample genome probing. Appl. Environ. Microbiol. 63, 1785-1793.

Toran, L., and Harris, R. F. (1989). Interpretation of sulfur and oxygen isotopes in biological and abiological sulfide oxidation. Geochim. Cosmochim. Acta 53, 2341-2348. doi: 10.1016/0016-7037(89)90356-6

Urbansky, E. (2002). Perchlorate as an environmental contaminant. Environ. Sci. Pollut. Res. 9, 187-192. doi: 10.1007/BF02987487

Urbansky, E. T. (1998). Perchlorate chemistry: implications for analysis and remediation. Bioremed. J. 2, 81-95. doi: 10.1080/10889869891214231

Urbansky, E. T., and Brown, S. K. (2003). Perchlorate retention and mobility in soils. J. Environ. Monit. 5, 455-462. doi: 10.1039/b301125a

Vance, I., and Thrasher, D. R. (2005). "Reservoir souring: mechanisms and prevention," in Petroleum Microbiology, eds B. Ollivier, and M. Magot (Washington, DC: ASM Press), 123-142.

Voordouw, G., Armstrong, S. M., Reimer, M. F., Fouts, B., Telang, A. J., Shen, Y., et al. (1996). Characterization of $16 \mathrm{~S}$ rRNA genes from oil field microbial communities indicates the presence of a variety of sulfate-reducing, fermentative, and sulfide-oxidizing bacteria. Appl. Environ. Microbiol. 62, 1623-1629.

Voordouw, G., Grigoryan, A. A., Lambo, A., Lin, S., Park, H. S., Jack, T. R., et al. (2009). Sulfide Remediation by pulsed injection of nitrate into a low temperature canadian heavy oil reservoir. Environ. Sci. Technol. 43, 9512-9518. doi: $10.1021 /$ es $902211 \mathrm{j}$

Widdel, F., Hansen, T., Balows, A., Truper, H., Dworkin, M., Harder, W., et al. (1992). "The dissimilatory sulfate-and sulfur-reducing bacteria," in The Prokaryotes: A Handbook On The Biology Of Bacteria: Ecophysiology, Isolation, Identification, Applications, 2nd Edn., Vol. 1, eds A. Balows, H. G. Trüper, M. Dworkin, W. Harder, and K.-H. Schleifer (New York, NY: Springer-Verlag), 583-624.

Wrighton, K. C., Agbo, P., Warnecke, F., Weber, K. A., Brodie, E. L., Desantis, T. Z., et al. (2008). A novel ecological role of the Firmicutes identified in thermophilic microbial fuel cells. ISME J. 2, 1146-1156. doi: 10.1038/ismej. 2008.48

Youssef, N., Elshahed, M. S., and McInerney, M. J. (2009). Microbial processes in oil fields: culprits, problems, and opportunities. Adv. Appl. Microbiol. 66, 141-251. doi: 10.1016/S0065-2164(08)00806-X

Conflict of Interest Statement: The corresponding author has an IP submission based on souring control. The Associate Editor M. Youngblut declares that despite being affiliated to the same institution as the author(s) J. D. Coates, the review process was handled objectively and no conflict of interest exists. The authors declare that the research was conducted in the absence of any commercial or financial relationships that could be construed as a potential conflict of interest.

Received: 27 March 2014; accepted: 09 June 2014; published online: 26 June 2014. Citation: Engelbrektson A, Hubbard CG, Tom LM, Boussina A, Jin YT, Wong H, Piceno YM, Carlson HK, Conrad ME, Anderson G and Coates JD (2014) Inhibition of microbial sulfate reduction in a flow-through column system by (per)chlorate treatment. Front. Microbiol. 5:315. doi: 10.3389/fmicb.2014.00315

This article was submitted to Microbial Physiology and Metabolism, a section of the journal Frontiers in Microbiology.

Copyright (c) 2014 Engelbrektson, Hubbard, Tom, Boussina, Jin, Wong, Piceno, Carlson, Conrad, Anderson and Coates. This is an open-access article distributed under the terms of the Creative Commons Attribution License (CC BY). The use, distribution or reproduction in other forums is permitted, provided the original author(s) or licensor are credited and that the original publication in this journal is cited, in accordance with accepted academic practice. No use, distribution or reproduction is permitted which does not comply with these terms. 